\title{
ESTRATÉGIAS DE RESISTÊNCIA POSSIBILITANDO O DEBATE DE GÊNERO E SEXUALIDADE NA ESCOLA
}

\author{
Lara Torrada ${ }^{1}$ \\ Paula Regina Costa Ribeiro ${ }^{2}$ \\ Juliana Lapa Rizza ${ }^{3}$
}

\begin{abstract}
RESUMO
Este artigo tem como objetivo analisar algumas estratégias de resistência produzidas em um projeto-experiência que visa à promoção das discussões de gênero e sexualidade no espaço escolar. $O$ trabalho articula problematizações acerca dos mecanismos de poder e estratégias de resistência de professoras e de um professor que participaram do Projeto Escola Promotora da Igualdade de Gênero. As perspectivas que organizaram as análises tomam como inspiração os estudos foucaultianos, de gênero e sexualidade. Os dados da pesquisa foram produzidos a partir de entrevistas e de grupo de discussão. Nas análises, foi possível perceber estratégias promovidas pelas/pelo professoras/professor, como: trabalhar com a temática utilizando termos ou assuntos de "maior aceitação" pela sociedade; incorporar a temática aos conteúdos das disciplinas; manter um diálogo com as famílias e comunidade sobre o desenvolvimento do projeto; lutar pela inclusão da temática nos documentos que fornecem diretrizes educacionais, entre outras estratégias de resistências, buscando manter a problematização e as discussões referentes às temáticas de gênero e sexualidade em suas salas de aula. Por fim, para possibilitar um espaço escolar menos discriminatório e sexista, é fundamental que existam propostas que promovam resistências e que possibilitem a problematização e o debate das questões de gênero e sexualidade na escola.
\end{abstract}

Palavras-chave: Gênero. Sexualidade. Resistências. Escola.

\section{RESISTANCE STRATEGIES MAKING POSSIBLE GENDER AND SEXUALITY DEBATE AT SCHOOL}

\begin{abstract}
This article analyzes some strategies of resistance produced in a project-experience promoting the discussions of gender and sexuality in the school space. We articulate questions on the mechanisms of power and strategies of resistance of three teachers who participated on the "Projeto Escola Promotora da Igualdade de Gênero". The theoretical framework used in our analysis is inspired by Foucaultian studies, on gender and sexuality. Data was collected in interviews and discussion groups. We were able to identify the strategies promoted by the teachers, such as: working with the theme by using terms and subjects of greater general acceptance; incorporate the theme into the content of existing courses; maintain a dialogue with the families and the community about the development of the project; advocate for inclusion of the theme in the documents that provide educational guidelines, among others, seeking to maintain the articulation and the discussions on the theme in their classrooms. Finally, it is fundamental to have proposals that promote the resistance and allow the problematization and the debate on gender and sexuality issues to enable a less discriminatory and sexist school space.
\end{abstract}

Keywords: Gender. Sexuality. Resistance. School.

Recebido em: $31 / 5 / 2019$

Aceito em: 29/7/2019

\footnotetext{
Psicóloga formada, mestre em Educação em Ciências: Química da Vida e Saúde e doutoranda em Educação e Ciências pela Universidade Federal do Rio Grande (Furg). Integrante do Grupo de Pesquisa Sexualidade e Escola (Gese - Furg). Membro no Núcleo de Gênero, Raça e Sexualidade do ConseIho Regional de Psicologia - CRP. http://lattes.cnpq.br/2390643756726967. https://orcid.org/0000-0003-0088-7310. lara.torrada@hotmail.com

2 Doutora em Ciências Biológicas pela Universidade Federal do Rio Grande do Sul - UFRGS. Professora do Instituto de Educação e dos Programas de Pós-Graduação: Educação em Ciências e Educação Ambiental da Universidade Federal do Rio Grande - Furg. Pós-Doutorado na Escola Superior de Educação de Coimbra/Instituto Politécnico de Coimbra. Pesquisadora do Grupo de Investigación en Educación y Sociedad (Gies). Líder do Grupo de Pesquisa Sexualidade e Escola (Gese), atuando principalmente nos seguintes temas: corpos, gêneros e sexualidades. Bolsista produtividade 1C do CNPq. http://lattes.cnpq.br/0516745823012125. https://orcid.org/0000-0001-7798-996X.pribeiro.furg@gmail.com

3 Graduação em Pedagogia - Licenciatura com Habilitação nos Anos Iniciais, Mestrado e Doutorado em Educação Ambiental pela Universidade Federal do Rio Grande (Furg). Pós-doutoranda no Programa de Pós-Graduação em Educação em Ciências. Pesquisadora do Grupo de Pesquisa Sexualidade e Escola (Gese/Furg). Coordenadora do Projeto Escola Promotora da Igualdade de Gênero. Tem experiência na área de educação, com ênfase nas questões de corpos, gêneros e sexualidades na Educação Básica e na formação de professores/as. http:// lattes.cnpq.br/0187459530198196. https://orcid.org/0000-0003-0985-0282.ju_rizza@yahoo.com.br
} 
Estamos atravessando um tempo em que a educação vem sofrendo um cerceamento, no que respeita às discussões de gênero e sexualidade, tendo em vista os movimentos conhecidos como "ideologia de gênero" e "escola sem partido", com discursos ultraconservadores que buscam "instaurar um clima de pânico moral contra grupos sociais e sexualmente vulneráveis e marginalizados, por meio do acionamento de variadas estratégias discursivas, artifícios retóricos, repertórios, redes de intertextualidade, etc." (JUNQUEIRA, 2017, p. 29).

Nesse sentido, segundo Rogério Junqueira (2017), em nome de valores morais tradicionais, da naturalização da família heterossexual, da maternidade e da heterossexualidade, algumas manifestações e ações relacionadas às discussões de gênero vêm sendo depreciadas por discursos jurídicos, discursos religiosos e discursos familiares.

Esses movimentos e manifestações contrárias à problematização da temática de gênero, no espaço da escola, é impulsionada no ano de 2014 com a elaboração e instauração do Plano Nacional de Educação (PNE). O PNE que, antes da sua aprovação apresentava a seguinte orientação: "São diretrizes do PNE a superação das desigualdades educacionais, com ênfase na promoção da igualdade racial, regional, de gênero e de orientação sexual", após a votação na Câmara dos Deputados, é modificado em sua versão final, defendendo a erradicação de todas as formas de discriminação (REIS; EGGERT, 2017). Esse movimento de cerceamento no PNE também se fez presente nos Estados brasileiros, com a tramitação dos Planos Estaduais de Educação e, posteriormente, nos municípios com os Planos Municipais de Educação.

Na contramão desse movimento denominado "antigênero" (JUNQUEIRA, 2017, p. 44), como forma de resistência, o espaço da escola, na condição de uma instituição laica, tem apresentado propostas educacionais inclusivas, reconhecendo o pluralismo, promovendo ações que viabilizem a igualdade de gênero e sexual. Além disso, diferentes políticas públicas, bem como políticas públicas educacionais, têm validado e possibilitado que o debate das questões de gênero e de sexualidade estejam presentes no espaço escolar, como a Lei número 9.394/96, que estabelece a Lei de Diretrizes e Bases da Educação Nacional (LDB), os Parâmetros Nacionais Curriculares (PCNs) no eixo transversal "orientação sexual" (1997), a Resolução no 1, de 30 de maio de 2012, que estabelece Diretrizes Nacionais para a Educação em Direitos Humanos, bem como a Constituição Federal de 1988, Lei Maria da Penha e Estatuto da Criança e do Adolescente (ECA). Nesse sentido, é no atravessamento de diretrizes que preveem a "diversidade", a "liberdade", o "respeito", a "tolerância" e o "pluralismo", presentes nas políticas públicas e nas políticas públicas educacionais, que se desenvolvem ações que problematizam as questões de gênero e sexualidade no espaço escolar, fazendo movimentos de resistência, "provocando rachaduras nas fronteiras interpostas entre os saberes, construindo espaços de transgressão e práticas de liberdade" (CASTRO, 2014, p. 64).

Desse modo, ações de resistência fazem-se necessárias, pois há uma força conservadora e reacionária que busca exercer um controle das discussões de gênero e sexualidade no currículo escolar. Michel Foucault, em um de seus escritos, expunha que os pontos mais cerrados da rede relacionam-se aos discursos de gênero e sexualidade, tal como exposto a seguir: 
Notaria apenas que, em nossos dias, as regiões onde a grade é mais cerrada, onde os buracos negros se multiplicam, são as regiões da sexualidade e as da política: como se o discurso, longe de ser esse elemento transparente ou neutro no qual a sexualidade se desarma e a política se pacifica, fosse um dos lugares onde elas exercem, de modo privilegiado, alguns de seus mais temíveis poderes $(2014$, p. 9).

Logo, o autor nos possibilita pensar sobre as grades que limitam as discussões das questões de gênero e sexualidade, por serem temas tratados como tabu e permeados por um discurso de controle que delimita "o que", "como" e "em que" espaços sociais é possível abordar tais temáticas (FOUCAULT, 2014), visando à manutenção da norma de gênero e sexual. Nesse sentido, diferentes instâncias como família, escola, mídia, instituições religiosas, fazem um investimento que, "de forma articulada, reiteram identidades e práticas hegemônicas enquanto subordina, nega ou recusa outras identidades" (LOURO, 2000, p. 16), mantendo padrões heteronormativos, limitando maneiras de sermos homens e mulheres, e entendendo a identidade heterossexual como a central e "natural".

Assim sendo, as questões de gênero e sexualidade sempre estiveram presentes nas escolas, por esta ser uma instituição que, articulada a outras, exerce uma pedagogia de gênero e sexualidade "tais pedagogias culturais produzem valores e saberes, regulam condutas e modos de ser, fabricam identidades e representações e constituem certas relações de poder" (MAGALHÃES, 2013, p. 65). Desse modo, sendo a escola um espaço "generificado" e "sexualizado", que produz e reafirma estereótipos de gênero e sexualidade a meninas e meninos, esse também passa a ser um lugar potente em que tais temáticas façam parte como temas possíveis de questionamento, como questões a serem (des)construídas com alunas/os, professoras/es, equipe pedagógica e diretiva e comunidade escolar.

Nesse sentido, a partir deste contexto apresentado, da escola como um espaço sexualizado e generificado, das relações de poder instauradas sobre o gênero e a sexualidade e dos retrocessos e silenciamentos, perguntamo-nos: Como resistir, no espaço escolar, a essa ofensiva, que tem como proposta a retirada das discussões de gênero e sexualidade do ambiente educacional?

Para pensar acerca deste questionamento apresentamos, como objetivo ${ }^{4}$ deste artigo, analisar algumas estratégias de resistências ${ }^{5}$ produzidas em um projeto-experiência, que visa à promoção das discussões de gênero e sexualidade no espaço escolar. Essas resistências foram produzidas por sujeitos que integraram o Projeto Escola Promotora da Igualdade de Gênero, que possibilitou outros modos de pensar a construção dos gêneros e das sexualidades. Tal projeto foi uma iniciativa do Grupo de Pesquisa Sexualidade e Escola - Gese, vinculado à Universidade Federal do Rio Grande - Furg, que

\footnotetext{
Este artigo integra a pesquisa de Mestrado intitulada "Escolas Promotoras da Igualdade de Gênero: Tessituras de um projeto-experiência", que tem como objetivo analisar as possíveis experiências produzidas pelos/as participantes do Projeto Escola Promotora da Igualdade de Gênero.

5 Neste artigo tomamos a ideia de resistência a partir de Michel Foucault entendendo-a como ação, reação, efeito, invenções possíveis, diante de relações de poder (FOUCAULT, 2010).
} 
buscou apoiar ${ }^{6}$ professoras e professores que tivessem interesse em desenvolver ações para a promoção e reflexão acerca da igualdade de gênero em escolas da rede pública do município de Rio Grande - RS.

Este projeto, como um espaço de formação, possibilitou que os/as integrantes compartilhassem e produzissem experiências acerca das questões de gênero e sexualidade no espaço escolar, ou seja, "uma formação que investe na possibilidade de pensar diferentemente, olhar a partir de novos ângulos, exercitar o pensamento diante de situações cotidianas para as quais não há uma única resposta" (CASTRO, 2014, p. 18). Pensando e compreendendo o projeto desta forma, travamos algumas interlocuções com Jorge Larrosa, no que tange à experiência, e aventuramo-nos a nomear esse projeto de formação como um "projeto-experiência", 7 pois entendemos que acontecimentos foram experienciados no transcorrer do processo de formação, possibilitando, assim, que algo nos tocasse, nos acontecesse e nos transformasse, pois, ainda que tenhamos vivenciado diferentes situações ao longo do projeto, apenas algumas nos marcaram e foram capazes de nos transformar.

\section{RELAÇÕES DE PODER E ESTRATÉGIAS DE RESISTÊNCIAS: Tecendo Alguns Aportes Teóricos}

Com base em alguns aportes teóricos buscamos, neste artigo, travar algumas discussões sobre poder e resistência, com o intuito de compreender, a partir de Michel Foucault, como essas forças nos interpelam e produzem alguns dos entendimentos que temos sobre as questões de gênero e sexualidade, assim como a forma com que essas temáticas são produzidas e vivenciadas na sociedade e, consequentemente, no espaço escolar. Nesse sentido, ao tecer algumas interlocuções com a noção de poder em Foucault estamos entendendo-o como uma força fluida, em que os indivíduos ora estão em posição de exercê-lo, ora sofrem suas ações, ao mesmo tempo em que resistem a ele (FOUCAULT, 2018).

Se o poder fosse somente repressivo, se não fizesse outra coisa a não ser dizer não você acredita que seria obedecido? $\mathrm{O}$ que faz com que o poder se mantenha e que seja aceito é simplesmente que ele não pesa só como uma força que diz não, mas que de fato ele permeia, produz coisas, induz ao prazer, forma saber, produz discurso. Deve-se considerá-lo como uma rede produtiva que atravessa todo o corpo social muito mais do que uma instância negativa que tem por função reprimir (FOUCAULT, 2018, p. 44-45).

Nesse sentido, o poder não é negativo para Foucault, uma vez que possibilita o movimento. É uma relação de força que não está presente só no Estado e na polícia, ou que se exerça de cima para baixo como às vezes se imagina, mas em diferentes relações - pais sobre as/os filhas/os, filhas/os sobre pais, homens sobre as mulheres, mulheres

\footnotetext{
O projeto, que aconteceu ao longo do ano de 2017 e teve sua segunda edição no ano de 2018, contou com uma equipe denominada de tutoras e tutores, que apoiavam as professoras e o professor na elaboração das ações.

7 Projeto-experiência: a escolha pelo uso da meia-risca (-) entre as palavras "projeto" e "experiência" serve para ligar conceitos, "a meia-risca serve para conectar duas palavras relacionadas diretamente uma à outra. Geralmente, essa relação é de conflito, ligação ou direção". WIKIHOW. Como usar travessão. Acesso em: 7 de fevereiro de 2019. Disponível em: https://pt.wikihow.com/Usar-Travess\%C3\%A3o.
} 
sobre homens, professoras/es sobre alunas/os; cada relação apresenta métodos para manter e exercer o poder. Ademais, ele só se mantém por haver resistência, "porque há possibilidade de resistência e resistência real que o poder daquele que domina tenta se manter com tanto mais força, tanto mais astúcia, quanto maior for a resistência" (FOUCAULT, 2015, p. 227). Nesse sentido, onde há poder há resistência, são duas forças que fazem parte da mesma relação, pois onde não houver possibilidade de resistir temos uma situação de violência e não de poder.

Por outro lado, para Foucault, o poder tem "necessidade de mecanismos contínuos, reguladores e corretivos" (2017, p. 155), que deem conta de dois pontos em que se desenvolveu e organizou o poder sobre a vida da espécie humana. Em primeiro lugar, garantir a disciplina dos corpos - "corpo como máquina: no seu adestramento, na ampliação de aptidões, na extorsão de suas forças... na integração em sistemas de controle eficazes e econômicos" (Ibid, 2017, p. 150); em segundo lugar, a tecnologia de poder destinada ao corpo-espécie, entendido como um aporte de processos biológicos: nascimento, longevidade, nível de saúde, garantindo, assim, a regulação das populações a partir do controle sobre a natalidade e mortalidade, economia, habitação e migração.

Segundo o autor, são as diferentes instituições - família, escola, governo, igrejas que asseguram a disciplina e a regulação em busca de uma sociedade normalizadora, a partir de um poder que tem de qualificar, medir, avaliar e hierarquizar (Ibid, 2017). Além disso, é a sexualidade "o alvo central de um poder que se organiza em torno da gestão da vida" (FOUCAULT, 2017, p. 159), pois ela se encontra nos dois pontos em que se organizou o poder: os corpos e a regulação das populações. A sexualidade está presente na biologia dos corpos, na organização da sociedade, das relações e das constituições familiares.

Assim, ao pensar esse exercício do poder, que busca a restauração da norma de gênero e da heteronormatividade, quando problematizamos algumas questões referentes à sexualidade e ao gênero no espaço da escola, deparamo-nos com a atuação de um poder que hierarquiza e, consequentemente, coloca às margens da sociedade aquelas identidades que não se enquadram nas normas de gênero e sexualidade. Além disso, ainda sobre a atuação do poder, é possível perceber que alguns discursos são legitimados na condição de temáticas permitidas no espaço escolar, como gravidez na adolescência e prevenção de infecções sexualmente transmissíveis, visando a uma forma de controle do corpo e da população.

Há, contudo, sempre forças que resistem ao poder, que reivindicam a vida, a liberdade de viver, pois, para haver uma relação de poder, é necessário que o outro sujeito (ou os outros) sobre o qual está se exercendo o poder seja um "sujeito de ação; que se abra diante da relação de poder, todo um campo de respostas, reações, efeitos, invenções possíveis" (FOUCAULT, 2010, p. 288). Nesse sentido, poder é uma ação sobre ações, ações como estratégia de luta, ações de resistência. Assim, Michel Foucault assenta alguns pontos pelos quais se faz resistência, se luta.

Temos aí um processo bem real de luta; a vida como objeto político foi de algum modo tomada ao pé da letra e voltada contra o sistema que tentava controlá-la. Foi a vida, muito mais do que o direito que se tornou o objeto das lutas políticas, ainda que estas últimas se formulem através de afirmações de direito. $O$ "direito" à vida, 
ao corpo, à saúde, à felicidade, à satisfação das necessidades, o "direito", acima de todas as opções ou "alienações", de encontrar o que se é e tudo o que se pode ser (2017, p. 157).

Diante desta ideia de luta como estratégia de resistência à "norma" que vem para controlar, com a pretensão de disciplinar os corpos e regulamentar a população (FOUCAULT, 2010), o poder só se faz possível onde houver liberdade e possibilidade de diferentes condutas e modos de comportamento, só se faz possível à medida que os sujeitos possam reagir, possam ser ação e resistência.

Segundo Marlucy Paraíso, "resistência é movimento através do qual uma pessoa, um grupo, um povo ou uma multidão diz: chega! Eu não aceito mais isso! E mostra, com sua recusa, que considera injusto o risco de sua vida" (2016, p. 389). O "não" passa a ser só o começo de uma força que tem de seguir, caminhar, movimentar-se e sugerir estratégias que driblem essa onda reacionária, a qual vem para controlar o currículo e práticas pedagógicas das/os professoras/es.

Nesse sentido, entendendo resistência como uma força que busca outros possíveis, que suscita discussões, que instiga a crítica, que questiona verdades, buscamos tecer algumas interlocuções com os sujeitos que integraram esse projeto-experiência. Este projeto possibilitou que as/os professoras/es participantes desenvolvessem ações que suscitaram o debate da temática de gênero e sexualidade, problematizando alguns tabus relacionados ao tema, bem como a possibilidade de repensar algumas formas de compreender e viver o gênero, os prazeres e os corpos. Assim, diante do momento de cerceamento do que pode e do que não pode ser, falando sobre questões de gênero e sexualidade no espaço escolar, as atividades e ações propostas por cada professora/ professor estabeleceram-se como estratégias de resistência, pois foram ações de luta que visaram a romper com normas, suscitaram a liberdade dos corpos, da vida, das relações e dos modos de ser família.

\section{ESTRATÉGIAS DE PRODUÇÃO E ANÁLISE DE DADOS DO PROJETO-EXPERIÊNCIA}

Ao entender a resistência como força e estratégia que impulsiona ao movimento, que possibilita um rompimento às regras, bem como outros modos de pensar, viver e sermos sujeitos, analisamos os movimentos de resistência narrados pelas/os participantes do projeto-experiência no desenvolvimento de ações sobre as questões de gênero e sexualidade no espaço da escola. Foram movimentos individuais e também coletivos, resistindo a diferentes relações de poder, desde a direção das escolas, outras/ os colegas de trabalho, familiares e alunas/os, até o poder Legislativo e a comunidade do município.

Para nos aproximarmos das narrativas, realizamos entrevista ${ }^{8} \mathrm{com} 18$ professoras e 1 professor que participaram do projeto-experiência, em 2017, e que se mantiveram na edição de 2018 e se dispuseram a participar desta pesquisa. Rosa Maria Hessel Silveira (2007) entende que olhamos as entrevistas

As professoras e o professor que participaram das entrevistas assinaram um termo de consentimento para participarem da pesquisa. 
[...] como eventos discursivos complexos, forjados não só pela dupla entrevistador/entrevistado, mas também pelas imagens, representações, expectativas que circulam - de parte a parte - no momento e situação de realização das mesmas e, posteriormente, de sua escuta e análise (p. 118).

Nesse sentido, as entrevistas são produções discursivas, nas quais não há uma verdade única e definitiva, elas permitem pensar na construção de subjetividades. Com as entrevistas, foi possível nos aproximarmos de cada professora e professor, a fim de conhecer suas ações e, principalmente, os sentidos que esse envolvimento com o Projeto Escola Promotora da Igualdade de Gênero teve para elas e ele. Ainda foi possível conhecer e investigar os desafios que encontraram, as experiências que produziram e os movimentos de resistência que realizaram para manter o projeto.

Outra estratégia para a produção dos dados foi a realização de um grupo de discussão ${ }^{9}$ com essas professoras e com o professor, entendido como uma prática investigativa, em que buscamos perceber a opinião coletiva do grupo, não sendo a soma individual de cada um, mas o que se produziu a partir do encontro (WELLER, 2013). O grupo de discussão veio com o intuito de pensarmos que experiências eram compartilhadas, possibilitando que, ao falar suas experiências para o grupo e ao ouvir outras experiências, outros sentidos e significados foram se produzindo. Também foi possível pensar, coletivamente, os efeitos e resistências para o desenvolvimento do projeto e, consequentemente, para a discussão de gênero na escola.

As professoras e o professor tinham idades entre 27 e 54 anos e tempo de docência entre 2 e 30 anos. Elas e ele têm formações em Educação Física, Pedagogia, Ciências Biológicas, História Licenciatura, Geografia Licenciatura, Letras Português, Letras Português/Espanhol e Educação Artística. Estes profissionais desenvolveram o projeto em escolas municipais e estaduais, em que atuam como docentes, em diferentes bairros do município.

Assim, a partir das narrativas dessas professoras e do professor, trazemos, neste artigo, algumas estratégias de resistência produzidas e relatadas por ele e por elas que se desafiaram a debater e promover a igualdade e equidade de gênero no espaço escolar. Nesse sentido, retomamos Paraíso que descreve resistência como "força inventiva que mobiliza e cria possíveis" (2016, p. 389). Essa força abre espaços, abre caminhos, cria possibilidades e promove um existir de outro modo (PARAísO, 2016). Uma força que entendemos, a partir de Michel Foucault, como uma estratégia, uma reação a um poder e que precisou estar potente neste projeto para que as discussões se mantivessem, para que outras possibilidades de ver e viver o gênero e a sexualidade pudessem ser pensadas no ambiente da escola.

As estratégias de análise consistiram em olhar as experiências narradas pelo professor e pelas professoras que emergiram nas entrevistas e no grupo de discussão. Para tanto, entendemos a narrativa como uma modalidade discursiva, pois, segundo Larrosa,

As professoras e o professor que participaram do grupo de discussão assinaram um termo de consentimento para participarem da pesquisa. 
a narrativa não é lugar de irrupção da subjetividade, senão a modalidade discursiva que estabelece a posição do sujeito e das regras de sua construção em uma trama. Nesse mesmo sentido, o desenvolvimento da nossa autocompreensão dependerá de nossa participação em redes de comunicação onde se produzem, se interpretam e se medeiam histórias (1996, p. 471-472).

Nesse sentido, as experiências-narrativas encontram-se implicadas com as práticas sociais e a rede de discursos em que se encontram inseridas. Assim, entendemos que as entrevistas e o grupo de discussão funcionaram como estratégias para a produção dos dados da pesquisa, para que os sujeitos pudessem narrar os fatos vivenciados e ao narrar pudessem ressignificar suas vivências, e também como possibilidade para a emergência de algumas estratégias de resistência, que apresentamos a seguir.

\section{RESISTÊNCIA EM OPERAÇÃO}

Com base na análise das narrativas, ${ }^{10}$ é possível perceber algumas estratégias de resistências que insurgiram no decorrer do Projeto Escola Promotora da Igualdade de Gênero, para tornar possível o debate de gênero e sexualidade nas escolas. Por meio dos dados, notamos que estratégias foram operadas pelas professoras e pelo professor, de acordo com algumas especificidades, como a temática escolhida, o público, os embates na comunidade escolar. Desse modo, as estratégias foram pensadas a partir dos entraves que foram aparecendo com a proposta de discutir gênero e sexualidade na escola. Ao olharmos essas narrativas, fomos tecendo algumas discussões, juntamente com diferentes autores/as, entendendo alguns movimentos empreendidos pelas professoras e pelo professor como resistência.

Foucault destaca que há uma multiplicidade de pontos de resistências presentes em toda a rede de poder, "resistências, no plural, que são casos únicos: possíveis, necessárias, improváveis, espontâneas, selvagens, solitárias, planejadas, violentas, irreconciliáveis, prontas ao compromisso, interessadas ou fadadas ao sacrifício" (2017, p. 104). Assim, apresentaremos narrativas diversas, resistências múltiplas, como as das professoras Thuane e Jerusa. ${ }^{11}$

Desse modo, iniciamos apresentando as narrativas de duas professoras, em que é possível perceber que a estratégia utilizada foi organizar atividades com as temáticas de gênero e sexualidade que não causassem tanto impacto devido ao tabu que as envolvem. Assim, as professoras Thuane e Jerusa pensaram de forma estratégica em temas que, segundo elas, possuem mais aceitação das famílias e da sociedade, de forma geral.

A gente nota como os pais têm resistência, a ponto de perguntarem pra coordenadora porque as professoras estavam falando de sexo em aula. Sendo que ela pegou e disse "não, a gente não tá falando em sexo em sala de aula, a gente está falando sobre o tema amor... tem todo um embasamento, tem todo um apoio técnico por detrás do pedagógico, né. E o aluno tá fazendo isso com o consentimento de vocês" (Thuane, entrevista, 2018).

\footnotetext{
${ }^{10}$ As narrativas das professoras e do professor estão apresentadas em itálico ao longo do texto.

${ }^{11}$ Pautados em princípios éticos e a fim de garantir o anonimato dos sujeitos participantes da pesquisa, utilizamos pseudônimos, preservando, assim, a identidade dos sujeitos. 
Embora lá na escola a gente teve que ir por um caminho não tanto dos gêneros como a gente gostaria, a gente foi mais pelo lado familiar, pelo lado das diferentes composições familiares das famílias deles... um dos critérios principais, foi a aceitação... porque quando levaram a placa lá para escola teve uma mãe que botou no Face, falando mal da própria escola onde estavam os filhos, falando que ela não foi consultada e tal. Daí a gente ficou um pouco retraído de começar, daí a gente resolveu começar com a família (Jerusa, entrevista, 2018).

As professoras Thuane e Jerusa relataram que preferiram trabalhar com palavras como "amor" e "família", de modo que as palavras gênero, sexualidade ou sexo não estivessem como foco principal das discussões, pois ao falarmos sobre gênero e sexualidade há um vocabulário autorizado com regras de decência que filtram as palavras (FOUCAULT, 2017). Nesse sentido, Foucault (2014) destaca a interdição do discurso como um mecanismo de poder que produz efeito, e afirma que não se pode falar de tudo, em todos os espaços, e que qualquer um não pode falar de qualquer coisa, entretanto, onde há mecanismos de poder há enfrentamentos, há a possibilidade de resistir, "não há relações de poder que sejam completamente triunfantes e cuja dominação seja incontornável" (FOUCAULT, 2015, p. 227). Desse modo, as professoras criaram como estratégia o uso dos temas que entenderam como "autorizados", e puderam, a partir disso, pensar outros discursos sobre amor e família.

Assim, a professora Thuane viu na temática "amor" uma possibilidade para colocar em pauta as diferentes possibilidades de relações afetivas, impulsionada pela situação de ter em sua sala de aula um casal de lésbicas, e fez disto uma estratégia de resistência, que permitiu as discussões de gênero e sexualidade.

[...] a família não aceitava a homossexualidade, né, com agressão física, os pais culpavam a escola por tá estimulando. Então, foi um período bem difícil, assim! Ao mesmo tempo que elas sabiam, elas se viam como lésbicas, a família não aceitava. Os colegas ficavam, também, sem saber como que iam lidar com a situação, e elas próprias! Então, o nosso tema saiu justamente disso, porque a gente sentiu que a gente precisava fazer alguma coisa, né. Porque o aluno vem pra ti e diz "O que eu faço?" (Thuane, entrevista, 2018).

Nesse sentido, entendemos que as questões de gênero e sexualidade estão no espaço da escola, dentro das salas de aula, estão nas relações que os sujeitos vão estabelecendo nos espaços em que circulam. De maneira semelhante, a professora Jerusa trabalhou, a partir de livros infantis, as diferentes configurações familiares. Para tanto, trouxe para a sala de aula outras realidades, as quais foram discutidas, possibilitando às/aos alunas/os a percepção das múltiplas maneiras de ser família. Abordar essas temáticas é estar sensível ao que se passa na vida de cada estudante e que se apresenta na sala, "afinal, o professorar é profissão que trata da vida, que trata com vidas que só querem viver, vivenciando, sem juízo de valor, suas inquietantes experiências" (PARAÍSO, 2016, p. 407).

Neste movimento de estar atento à sala de aula, de se colocar sensível às diferentes realidades, a professora Sônia utilizou como estratégia, para possibilitar as discussões de gênero e sexualidade, atividades que tiveram como foco o respeito às dife- 
renças e a temática do preconceito em uma turma de Educação Infantil, por meio de leituras de livros infantis, problematizando as diferenças que apareciam na turma. A professora diz:

[...] como eles são crianças pequenas eu não quis me aproximar muito na questão da sexualidade em si, eu quis deixar a coisa mais superficial porque a gente sabe que sofre muita resistência dos pais né, "como que estás trabalhando esse tipo de assunto com meu filho, ele tem seis, sete anos, eles são pequenos ainda", então eu quis mais trabalhar no sentido de preconceito (Sônia, entrevista, 2018).

Essa narrativa nos suscita pensar novamente que, tendo em vista que alguns discursos são permitidos, a professora usa a estratégia de discutir o combate ao preconceito para possibilitar outros modos de viver os gêneros e as sexualidades. Também cabe apontarmos que, a partir desta narrativa, ao falar da objeção dos pais ao dizerem que os/as filhos/as são pequenos para trabalhar os assuntos da sexualidade, há um discurso da criança inocente e assexuada (RIBEIRO, 2002), com a concepção de que alguns debates não devem ser feitos com elas, por exemplo, discussões sobre diferentes identidades de gênero e sexual, debates sobre diferentes configurações familiares e sobre o conhecimento dos órgãos genitais.

Suscitar discussões e debates com a criança, entretanto, possibilita que ela exercite o pensamento e se coloque como sujeito ativo, com capacidade de pensar e argumentar sobre o que lhe toca, podendo ser potente para o autoconhecimento, para o cuidado consigo e com o outro, construir valores, opiniões e podendo transformar-se (XAVIER FILHA, 2018b).

No mesmo sentido da narrativa da professora Sônia, que traz como ponto nodal a contestação da família sobre o debate de gênero e sexualidade no espaço da sala de aula, outras narrativas de professoras também fazem esse apontamento. Tal intervenção das famílias é acalentada por este momento em que vivenciamos uma estratégia de poder, que distorce e defende que o debate de gênero é uma ideologia contrária aos interesses da família tradicional. Nesse sentido, Paraíso afirma:

As estratégias de poder de amedrontar as famílias, de usar chamadas claramente distorcidas e o próprio nome dado ao projeto - Ideologia de gênero - são cuidadosamente colocadas em ação, e têm se mostrado eficientes tanto para desqualificar os estudos e teses de gênero - que dizem que gênero é uma construção histórica e cultural construída em meio a relações de poder- como para convencer pessoas de que gênero é uma ideologia e um ataque à família (2016, p. 401).

Desse modo, percebemos, a partir das narrativas das professoras que participaram desse projeto-experiência, os efeitos desses discursos e o pânico do que pode ou não estar sendo "ensinado" aos filhos e filhas na escola. Amanda, professora e participante do projeto, inconformada com uma situação numa turma de 9o ano, conta: $O$ pai falou que a escola que tinha influenciado ele (referindo-se ao aluno que se reconhecia como homossexual). Da onde que a escola vai influenciar? E isso, assim, ó... Tiraram o menino, de uma hora pra outra e tava se formando, no 9o ano. Passou a vida inteira na escola, tiraram. Sabe? (entrevista, 2018). 
A narrativa da professora Amanda expressa esse amedrontamento, juntamente com um conjunto de informações distorcidas tal qual nos elucida Paraíso na citação anterior, quando narra a ideia deturpada deste pai de que, ao problematizar gênero e sexualidade na escola, seu filho estaria sendo influenciando em relação aos seus desejos sexuais. É neste ponto que o movimento "antigênero" manifesta-se em busca de um silenciamento "em nome do 'direito a uma escola não ideológica' ou a uma 'escola sem gênero'” (JUNQUEIRA, 2017, p. 44), entendendo que possibilitar informações, no que tange às múltiplas formas de viver o gênero e a sexualidade, poderá induzir as crianças e adolescentes a vivenciar outras expressões de gênero e de sexualidade que fujam à heteronormatividade. Nesse sentido, Castro afirma que "ao formularem-se as questões concernentes à escola e às relações pedagógicas, parece haver uma recusa ou uma resistência às narrativas sobre as sexualidades e relações de gênero. Embora sejam parte desses currículos, exatamente porque constituem os sujeitos e suas experiências" (2014, p. 68). Assim, estes movimentos, com um discurso de proteção às crianças e adolescentes, incentivam que as famílias interfiram na condução dos currículos das escolas, que as famílias digam o que pode ou não ser dito e trabalhado nas salas de aula e com isso o que é ou não função da escola.

Desse modo, precisamos ressaltar que, a partir de algumas narrativas das professoras, notamos que houve um movimento maior das famílias nas escolas, algumas fazendo acusações sem conhecimento e outras em busca de informações, como é possível perceber na narrativa das professoras Mônica e Fabiane, que desenvolveram uma oficina com o título "Diversidade", que acontecia semanalmente na escola para estudantes do 10 ao 7을 ano do Ensino Fundamental. As temáticas envolveram debates sobre questões étnico-racial, sobre binarismos de gênero e uma atividade com o título "menino ser valente, não é ser violento". Mônica narra uma situação que ocorreu em meio a uma roda de conversa, que fazia parte das atividades do projeto:

Num determinado momento, uma outra professora entra com uma mãe, a mãe olhou e disse "Não, só queria ver". Depois a professora veio conversar com a gente, que a mãe estava preocupadíssima, porque a filha tinha falado que ia ter uma roda de conversa sobre transexualidade, sobre sexualidade, (...) Ai ela entrou $e$ saiu, tranquila. E ela disse "Ai, era isso? Elas tão conversando? É só uma conversa?" Então, eu acho que é muito isso do que tá sendo exposto fora, sabe? (Mônica, entrevista, 2018).

Esta narrativa expressa este movimento de alerta e pânico moral, que "tem por objetivo evidente alertar a sociedade, provocando um temor coletivo sobre educação sexual, e discussão sobre gênero e sexualidade nas instituições educativas" (XAVIER FILHA, 2018a, p. 136), gerando preocupação sobre o que é ensinado no espaço escolar. Quando essa mãe, da escola da professora Mônica, dispõe-se a verificar o que de fato estavam trabalhando, então ela se tranquiliza, pois passa a conhecer o trabalho e a proposta das professoras no que tange a essas temáticas. Nesse sentido, Constantina Xavier Filha afirma que "o debate público e dialógico precisa ocorrer para que possamos questionar; com isso, espera-se diminuir os pânicos e os sustos/medos que eles provocam; somente o diálogo aberto poderá relativizar as preocupações/temor com os temas que 
envolvem sexualidades e gêneros nas infâncias" (2018a, p. 138). Desse modo, quando o diálogo não se faz possível, em virtude da desinformação, algumas situações podem tomar proporções violentas, agressivas e caluniosas.

Ainda sobre a desinformação ou informações equivocadas, que têm gerado algumas situações desagradáveis, com desdobramentos para além do espaço da escola, trazemos a vivência da professora Angelita que, juntamente a outra colega professora, com a qual desenvolveu o projeto, sofreu com a intervenção da mãe de uma aluna que fazia parte da turma de 60 ano, com a qual elas desenvolviam atividades do projeto. A mãe da aluna foi para a Câmara dos Vereadores, fazendo graves acusações acerca de um material que as professoras utilizaram para promover alguns debates na sala de aula. No plenário da Câmara dos Vereadores, que é filmado e transmitido em tempo real na TV Câmara do município e divulgado nas redes sociais, a mãe diz ${ }^{12}$ que a filha foi obrigada a ler na frente de toda turma, e reitera, "na frente dos meninos", "sobre transar, sobre bebida alcoólica, sobre menino não saber se ele é menino ou menina". Na mesma fala ela ainda afirma "como fica a cabeça da minha filha, se eu estou dizendo pra ela o que é o certo e vem a professora e diz outra coisa?"

A fala dessa mãe que estendeu mais algumas acusações, no plenário, acerca do trabalho desenvolvido pela professora, resultou em inúmeras postagens nas redes sociais, em apoio à mãe e outras à professora, chegando a um processo judicial que está em tramitação, no qual a mãe acusa a professora de utilizar material impróprio no trabalho desenvolvido.

A professora Angelita, que se manteve no projeto naquele ano e no ano seguinte, narrou na entrevista sobre esse episódio: o que ficou muito chato, que nós ficamos assim bem tristes, e até hoje, é porque a pessoa (mãe da aluna) não conheceu o trabalho, e saiu falando coisas que não era dos trabalhos, e não era mesmo. É bem uma pessoa ignorante mesmo, vamos dizer que as meninas vão ser meninos e os meninos vão ser meninas? (Entrevista, 2018).

A indignação de Angelita surge a partir das acusações que sofreu sem que pudesse explicar as atividades, sem que pudesse apresentar o que de fato estava sendo desenvolvido na escola. Angelita trabalhou com as/os alunas/os sobre as diferenças entre os gêneros, questões sobre as vestimentas, as profissões, o que é permitido e o que não é permitido para os meninos e para as meninas, por meio de leituras, vídeos e atividades com indicação adequada para a faixa etária da turma.

A partir desta situação é possível destacar que a professora Angelita vem sendo resistência, dado que se dispôs a trabalhar neste projeto, manteve-se nele no ano seguinte, apesar de todo o ocorrido. A professora, aliás, mantém-se resistente, seguindo no Projeto Escola Promotora da Igualdade de Gênero, desenvolvendo atividades com outras turmas na mesma escola. Para Paraíso, "resistir sempre implica medos e riscos... inclusive o risco de não sermos entendidas" (2016, p. 408) e mesmo incompreendidas seguir lutando e sendo enfrentamento a opressões e discriminações. Sendo resistência,

${ }^{12}$ Essa narrativa foi transcrita do vídeo que foi divulgado e compartilhado nas redes sociais. 
a professora Angelita diz: o nosso trabalho ele foi todo deturpado, o nosso trabalho, um trabalho muito legal que aconteceu na escola, ele sofreu um ataque, assim, imenso, mas, mesmo assim eu não desisti (entrevista, 2018).

Nas narrativas apresentadas é possível perceber que os embates com as famílias estiveram presentes em muitas escolas, e que existe uma relação de poder entre as famílias e a escola, ainda mais com alguns familiares utilizando-se de um discurso ultraconservador, que vem sendo disseminado por algumas instituições religiosas e por políticos que trabalham para o silenciamento e cerceamento da função da/do professor/a por meio de projetos de lei e movimentos, como o "Escola sem Partido", em que "vende-se o propósito de blindar a escola contra 'doutrinações', quando na realidade o alvo não é o proselitismo, mas o pensamento crítico e a experiência da pluralidade, os alicerces da escola" (GABATZ, 2018, p. 324). Há inúmeros casos, entretanto, de violência contra crianças, mulheres e sujeitos LGBT que acontecem, justamente, nas famílias ou com pessoas próximas (MACHADO et al., 2014).

Além disso, por vezes, as famílias reproduzem e perpassam valores culturais e normas sociais em que prevalecem desigualdades, preconceitos e violências. Desse modo, "lutamos para que as relações de gênero e as diferentes formas de viver a sexualidade saiam do lugar de silêncio acomodado, dos ensinamentos velados, das omissões covardes ou propositais" (PARAíso, 2018, p. 25), para a problematização da construção do masculino e do feminino, do heterossexual e do homossexual nos currículos (Ibid, 2018). Para tal, é necessário se fazer resistência e buscar estratégias que mantenham essas temáticas no espaço escolar e, também, para que sejam entendidas como parte do currículo escolar.

Assim, as professoras e o professor que participaram do projeto-experiência executaram ações como estratégia de luta e de resistência a diferentes relações de poder. Nesse sentido, o professor Ângelo, como estratégia para debater e levar para as/os estudantes a temática de gênero e sexualidade, promoveu atividades a partir do conteúdo que estava desenvolvendo sobre a Primeira e Segunda Guerra Mundial na disciplina de História:

Eu trabalhei toda questão conceitual com eles, das guerras, e que levou, os motivos que alguns alunos gostariam de trabalhar essa parte. E aí, eu fui trabalhando essa parte da guerra, mas sempre direcionando pra que eles fizessem uma leitura não só do conflito em si, mas sim, o que levou à perseguição das minorias, desde a $1^{\underline{a}}$ Guerra, o que levou, os motivos, esse nacionalismo exacerbado. Depois de trabaIhar essa questão mais conceitual com eles a gente trabalhou em cima do filme Milk [...] (Ângelo, entrevista, 2018).

O filme Milk: a voz da igualdade, que Ângelo menciona ter trabalhado com as/os estudantes, relata a história do primeiro homossexual assumido a ocupar um cargo público nos Estados Unidos, em 1977. Desse modo, em meio à disciplina de História, a turma pôde fazer algumas discussões sobre sexualidade, sobre preconceito e sobre como tais temáticas vão se constituindo na sociedade ao longo do tempo. Ângelo, ao narrar as discussões que promoveu, revela que não houve nenhum problema ao trabalhar a temática, que não houve pessoas contra seu trabalho, entretanto é fundamental considerarmos que o movimento de promover esses debates no espaço da escola é uma ação 
de resistência aos mecanismos de poder que buscam disciplinar e regular a sexualidade (FOUCAULT, 2017), possibilitando, por exemplo, o questionamento à heteronormatividade.

Nesse sentido, Silvio Gallo fala de uma educação que age nas brechas, que "a partir do deserto e da miséria da sala de aula, faz emergir possibilidades que escapem a qualquer controle" (2002, p. 175). São estratégias de resistência enfrentando mecanismos de poder como a de Ângelo, Thuane, Sonia, Mônica, Fabiane e das demais professoras que possibilitam a fuga da norma, o olhar para quem está à margem e a possibilidade de minimização das violências.

Esses mecanismos e relações de poder que estão no Estado e nas famílias também se fazem presentes na organização da própria escola. Segundo Foucault, a escola "se desenvolve através de todo um conjunto de comunicações reguladas (lições... ordens, exortações, signos codificados de obediência...), e através de toda uma série de procedimentos de poder (vigilância, recompensa e punição, hierarquia piramidal)" (2010, p. 288). Essa forma de organização resulta em relações de poder que, nesse projeto-experiência, apareceram em diferentes situações, como na relação de professora/ professor e direção:

O que me deixa um pouco entristecida é que eu faço esse caminho sozinha. Eu tenho respaldo da direção entre aspas, gostaria que tivesse mais, que os colegas entendessem a importância dessas coisas[...] (Maitê, grupo de discussão, 2018).

O tempo pra escrita eu tenho dificuldade, a própria educação não nos permite ter esse tempo, tu tem que trabalhar e cumprir a tua carga horária na sala de aula, porque se tu não tiver na sala de aula parece que tu não produz nada, que tu não faz nada [...] (Ângelo, grupo de discussão, 2018).

Também ocorreram entre as/os próprias/os colegas professoras/es, como aponta Ângelo:

Eu vou chutar o balde, eu acho que nossos colegas são uns bunda mole. Eles têm medo primeiro de participar de projeto porque projeto dá trabalho, e ainda um projeto que trabalhe com gênero, eles não querem esse tipo de enfrentamento (Ângelo, grupo de discussão, 2018).

Bem como em relação à Secretaria de Educação do município, como narra Sofia:

[...] no último Comed (Congresso Municipal de Educação) eu fui, eu falei "eu concordo que tem que ter no PPP (Projeto Político-Pedagógico), mas pra gente ficar bem amparado tem que ter um documento da SMEd (Secretaria de Município da Educação)", disseram bem assim: "ah não precisa disso, a gente apoia e vocês podem trabalhar o que quiserem porque a gente tá apoiando que essas questões sejam discutidas" e não quiseram fazer o documento. Ali me cortaram e deu, nunca mais (Sofia, grupo de discussão, 2018).

Nesse sentido, cabe ressaltar que algumas professoras e o professor expõem que sentem falta de maior apoio da rede de educação a que estão vinculados. Tendo em vista que, diante da circunstância ultraconservadora e de silenciamento, para mobilizar o debate da temática de gênero e sexualidade na escola, em alguns casos foi necessário defender a importância dessas discussões com os familiares e com a comunidade, 
por exemplo. Além disso, a falta de apoio desta rede torna mais dificultosa a prática das atividades. Essas professoras e o professor, no entanto, não deixaram de executar as ações, como é possível perceber na narrativa da professora Sofia, lutando para que essas temáticas estejam presentes no Projeto Político-Pedagógico (PPP), sendo consideradas um componente curricular.

Ademais, além do não apoio da rede de educação em alguns casos, cabe ressaltar que há um déficit em relação à formação docente, como aponta Roney Castro:

Se as relações de gênero e sexualidades dizem respeito, diretamente, aos modos como os sujeitos se relacionam com os outros e consigo mesmos, quais as implicações do silenciamento desses temas nos currículos de formação docente?... Por que é concebível que uma docente tenha desejável domínio de saberes disciplinares, mas ignore e produza relações excludentes nas escolas baseadas em sexismo, machismo, misoginia, homofobia (e tantos outros como racismo, xenofobia)? (2014, p. 69).

A não formação acadêmica e a omissão sobre as questões de gênero e sexualidade, conforme explicita Castro, produzem uma lacuna na hora de trabalhar com essas temáticas na sala de aula. Desse modo, "embora os professores/as entendam a importância da temática dentro do currículo escolar, alguns não têm formação adequada para levar essa discussão para suas práticas cotidianas em sala de aula" (ROSSI et al., 2012, p. 20). Nesse sentido, Maitê, no grupo de discussão, faz uma solicitação pela formação continuada: penso que esse respaldo mais teórico, da gente ler e esmiuçar o texto, nos ajuda mais a entender. Talvez se a gente tivesse a possibilidade de algum encontro encaminhar uma leitura prévia, trazer a coisa lida para debater (grupo de discussão, 2018).

A tudo isso, a todas essas diferentes relações que dificultaram, que tentaram impossibilitar, ou que simplesmente não fortaleceram o desenvolvimento das atividades pelo projeto, foram empregadas estratégias de resistência para garantir a autonomia da função do/a professor/a e possibilitar que as discussões de gênero e sexualidade estivessem no espaço da escola.

Promover discussões que envolvam as temáticas de gênero e sexualidade no espaço da escola "[...] é um ato de revolta e resistência. Revolta contra os fluxos instituídos, resistência às políticas impostas [...]" (GALLO, 2002, p. 173). Ser professora e professor, que promove a igualdade e equidade de gênero, é revoltar-se contra as discriminações e as violências que resultam de uma estrutura patriarcal, machista, sexista e misógina e ser resistente aos mecanismos de poder que legitimam esse funcionamento. Ser resistência, por sua vez, possibilita que outros sujeitos existam, que outras formas de viver o gênero e a sexualidade não sejam marginalizadas.

Fazer resistência "possibilita criar espaços de combates, de lutas, de insubordinação, de insurreição. A resistência é a criação de possíveis. Ela é força agenciadora que transforma e funda outras e novas relações" (PARAísO, 2016, p. 408). As estratégias de luta e resistência de cada professora e do professor os colocou em embate, desafiou relações, produziu e transformou o projeto-experiência, e principalmente, criou outros possíveis nas salas de aula. 


\section{POR FIM, MAS MANTENDO-SE EM RESISTÊNCIA}

O Projeto Escola Promotora da Igualdade de Gênero faz-se necessário quando essa vida generificada, binária, imersa em relações de poder, em que só existem duas possibilidades de ser, de viver, que (re)produz preconceitos, violências, vidas precárias, não serve mais para muitos/as. Ao dizer que o poder está presente em toda parte, "Foucault não nos diz que estamos fadados ao imobilismo, pelo contrário, nos ajuda a pensar nas ações e, sobretudo, nas formas de resistir" (XAVIER FILHA, 2018b, p. 98), como fizeram as professoras e o professor do projeto, priorizando estratégias para manter e defender que as diferentes formas de viver o gênero e a sexualidade, que já existem, possam ser vivenciadas sem medo, sem receio, no espaço da escola.

Analisar as entrevistas e o grupo de discussão nos possibilitou perceber que ainda que existam mecanismos de poder que dificultem, que busquem coibir e proibir que as temáticas de gênero e sexualidade estejam nos espaços da escola, as professoras e o professor utilizaram-se de diferentes estratégias para resistir, "resistir à estupidez. Resistir à tentativa de controle dos currículos e dos/as professores/as. Resistir à proibição de um pensamento crítico e político na escola. Resistir à proibição da discussão sobre gênero e sexualidade. Resistir à criminalização dos/as professores/as" (PARAísO, 2016, p. 403). Nesse sentido, pudemos perceber, a partir das análises, que uma das principais estratégias de resistência foi não utilizar as palavras "gênero" e "sexualidade" ao apresentar as atividades, ou seja, trabalhar com a temática utilizando termos ou assuntos de "maior aceitação" pelas famílias e sociedade, como preconceito, família, respeito e amor.

Outras estratégias de resistência também foram empregadas pelas professoras e pelo professor, entre as quais destacamos: a incorporação das temáticas de gênero e sexualidade nos conteúdos conceituais da disciplina ministrada pelo professor; a possibilidade de diálogo e informação com a comunidade escolar, referente ao trabalho que estava sendo desenvolvido; a continuidade no projeto, ainda que a professora tenha sofrido ataques ao seu trabalho; a luta pela inclusão das discussões de gênero e sexualidade em documentos que fornecem diretrizes para o processo educacional e a solicitação das professoras e do professor em relação a um adensamento teórico nesse espaço de formação continuada, que possibilitasse um aprofundamento dos estudos de gênero.

Também pode-se refletir que algumas estratégias de resistência foram mobilizadas pelo discurso da ideologia de gênero. Tendo em vista o movimento de pânico moral gerado pelos discursos ultraconservadores as professoras e o professor necessitaram acionar diferentes estratégias para manter as discussões e as atividades. Além disso, também foi possível notar que com esses discursos mais aflorados houve maior atenção das famílias ao que estava sendo trabalhado nas escolas, ficando explícitos, em algumas narrativas, um maior interesse e presença dos pais e/ou responsáveis nas atividades desenvolvidas na escola.

Diante do exposto, ao nos posicionarmos como resistência, enfrentando todos os desafios para incluir na escola e manter no currículo as problemáticas de gênero e sexualidade, nos colocamos em risco, entretanto "os/as diferentes com os quais lidamos todos os dias em nossas salas de aulas também não vivem muitos medos e muitos 
riscos? Não vivem medos e riscos inclusive relacionados a suas vivências de gênero e sexualidade?" (PARAísO, 2016, p. 408). Sabemos que vivem. Vemos e vivenciamos na escola os sofrimentos do cotidiano de cada um e cada uma que foge às normas, por isso seremos resistência enquanto a existência de alguém estiver em risco.

Por fim, tendo em vista os discursos que instauram e mantêm preconceitos, estereótipos, violências de gênero e de sexualidade, bem como as discriminações e opressões que se perpetuam na sociedade, é fundamental que existam propostas que promovam resistências e que possibilitem a problematização e o debate das questões de gênero e sexualidade na escola. É nesse sentido que o Projeto Escola Promotora da Igualdade de Gênero promove a formação de professoras e de professores, a fim de que possamos experimentar e vivenciar um espaço escolar diferenciado, possibilitando a formação de crianças e adolescentes que rompam com discursos hegemônicos referentes às questões de gênero e sexualidade, do mesmo modo que abre espaço para que os sujeitos que fogem ao padrão percebam suas vidas como possíveis.

\section{REFERÊNCIAS}

CASTRO, Roney Polato de. Experiência e constituição de sujeitos docentes: relações de gênero, sexualidade e formação em Pedagogia. 2014. 256p. Tese (Doutorado) - Programa de Pós-Graduação em Educação, Universidade Federal de Juiz de Fora, 2014.

EBC. Agência Brasil. Educação. Comissão da Câmara aprova texto-base do PNE e retira questão de gênero. Disponível em: http://agenciabrasil.ebc.com.br/educacao/noticia/2014-04/comissao-da-camara-aprova-texto-base-do-pne-e-retira-questao-de-genero. 2017. Acesso em: 15 nov. 2018.

FOUCAULT, Michel. A ordem do discurso. Aula inaugural no Collège de France, pronunciada em 2 de dezembro de 1970. São Paulo: Loyola, 2014.

FOUCAULT, Michel. Microfísica do poder. 8. ed. Rio de Janeiro; São Paulo: Paz e Terra, 2018.

FOUCAULT, Michel. Ditos e escritos. Estratégia, poder-saber. Rio de Janeiro: Forense Universitária, 2015. v. IV.

FOUCAULT, Michel. História da Sexualidade 1. A vontade de saber. 4. ed. Rio de Janeiro; São Paulo. Paz e Terra, 2017.

FOUCAULT, Michel. O sujeito e o poder. In: DREYFUS, Hubert; RABINOW, Paul. Uma trajetória filosófica. Para além do estruturalismo e da hermenêutica. 2. ed. Rio de Janeiro: Forense Universitária, 2010. p. 273295.

GABATZ, Celso. O movimento Escola Sem Partido e a criminalização ideológica na educação brasileira contemporânea. Revista Contexto \& Educação, ljuí: Editora Unijuí, v. 33, n. 104, p. 323-345, jan./abr. 2018. GALLO, Silvio. Em torno de uma educação menor. Educação e Realidade, Porto Alegre, v. 27, n. 2, p. 169178, jul./dez. 2002.

JUNQUEIRA, Rogério Diniz. "Ideologia de Gênero": a gênese de uma categoria política reacionária - ou: a promoção dos direitos humanos se tornou uma "ameaça à família natural"? In: RIBEIRO, Paula Regina Costa, MAGALHÃES, Joanalira Corpes (org.). Debates contemporâneos sobre Educação para a sexualidade. Rio Grande: Ed. da Furg, 2017. p. 25-52.

LARROSA, Jorge. Narrativa, identidad y desidentificación. In: LARROSA, Jorge. La experiência de la leitura. Barcelona: Laertes, 1996. p. 461-482.

LOURO, Guacira Lopes (org.). O corpo educado: pedagogias da sexualidade. Tradução dos artigos Tomaz Tadeu da Silva. Belo Horizonte: Autêntica, 2000. 176p.

MACHADO, Juliana Costa et al. Violência intrafamiliar e as estratégias de atuação da equipe de Saúde da Família. Saúde Soc., São Paulo, v. 23, n. 3, p. 828-840, Set. 2014. Disponível em: http://www.scielo. br/scielo.php?script=sci_arttext\&pid=S0104-12902014000300828\&lng=en\&nrm=iso. Acesso em: 20 jan. 2019. 
MAGALHÃES, Joanalira Corpes. Discutindo pedagogias culturais e representações de gênero. In: SILVA, Fabiane Ferreira da; MAGALHÃES, Joanalira Corpes; RIBEIRO, Paula Regina Costa; QUADRADO, Raquel Pereira. Sexualidade e escola: compartilhando saberes e experiências. 3. ed. rev. Rio Grande: Editora da Furg, 2013. p. 64-69.

PARAíSO, Marlucy Alves. A ciranda do currículo com gênero, poder e resistência. Currículo sem Fronteiras, v. 16, n. 3, p. 388-415, set./dez. 2016. Disponível em: http://www.curriculosemfronteiras.org/vol16iss3articles/paraiso.pdf. Acesso em: 20 jan. 2019.

PARAÍSO, Marlucy Alves. Fazer do caos uma estrela dançarina no currículo: invenção política com gênero e sexualidade em tempos do slogan "ideologia de gênero". In: PARAísO, Marlucy Alves; CALDEIRA, Maria Carolina da Silva (org.). Pesquisas sobre currículos, gêneros e sexualidades. Belo Horizonte: Mazza Edições, 2018. p. 23-52.

REIS, Tony; EGGERT, Edla. Ideologia de gênero: uma falácia construída sobre os planos de educação brasileiros. Revista Educ. Soc., Campinas, v. 38, n. 138, p. 9-26, jan./mar. 2017.

RIBEIRO, Paula Regina Costa. Inscrevendo a sexualidade: discursos e práticas de professoras das séries iniciais do Ensino Fundamental. 2002. 125p. Tese (Doutorado) - Universidade Federal do Rio Grande do Sul, Instituto de Ciências Básicas da Saúde. Curso de Pós-Graduação: Bioquímica, Porto Alegre, 2002.

ROSSI, Célia Regina; VILARONGA, Carla Ariela; GARCIA, Osmar Arruda; LIMA, Maria Teresa Oliveira. Gênero e diversidade na escola: reflexões acerca da formação continuada sobre assuntos da diversidade sexual. Revista Contexto \& Educação, ljuí, v. 27, n. 88, p. 6-34, jul./dez. 2012.

SILVEIRA, Maria Rosa Hessel. A entrevista na pesquisa em educação - uma arena de significados. In: COSTA, Marisa Vorraber (org.). Caminhos Investigativos II: outros modos de pensar e fazer pesquisa em educação. 2. ed. Rio de Janeiro: Lamparina Editora, 2007. p. 117-138.

WELLER, Wivian. Grupos de discussão: aportes teóricos e metodológicos. In: WELLER, Wivian; PFAFF, Nicolle (org.). Metodologias da pesquisa qualitativa em educação. 3. ed. Petrópolis, RJ: Vozes, 2013. p. 54-66.

WIKIHOW. Como usar travessão. Disponível em: https://pt.wikihow.com/Usar-Travess\%C3\%A3o. Acesso em: 7 fev. 2019.

XAVIER FILHA, Constantina. Brincar de fazer cinema com crianças: (des)propósitos, desafios e resistência em projeto de extensão. In: RIBEIRO, Paula Regina Costa (org.). Corpo, gênero e sexualidade. Resistência e (ocupa)ações nos espaços de educação. Rio Grande: Ed. da Furg, 2018b. p. 89-104.

XAVIER FILHA, Constantina. Gênero e sexualidade na infância: construção de pânicos morais. In: RIBEIRO, Paula Regina Costa, MAGALHÃES, Joanalira Corpes (org.). Interlocuções sobre gêneros e sexualidades na educação. Rio Grande: Ed. da Furg, 2018a. p. 123-140. 